\title{
As noções de dependência e de subdesenvolvimento na obra de Celso Furtado $^{1}$
}

\author{
Igor Zanoni Constant Carneiro Leão ${ }^{2}$
}

- Enviado em 20/04/2016

- Aprovado em 30/05/2016

\section{RESUMO}

Este artigo esclarece as relações entre dependência e subdesenvolvimento segundo Celso Monteiro Furtado. Elas foram alvo de um trabalho exaustivo desse autor em toda sua vasta produção e encontram-se clarificadas de forma lapidar em sua Obra Autobiográfica. Embora Furtado seja indubitavelmente nosso maior economista, e mais que isso, um dos maiores "intérpretes do Brasil", sendo por isso muito conhecido e reconhecido, os seus livros podem ser lidos sob muitas óticas, pois falam de um grande conjunto de problemas e temas, dentro da questão maior do desenvolvimento e da formação econômica e social do País. Todavia, as noções de dependência e de subdesenvolvimento são centrais, um núcleo duro em torno do qual seus inúmeros temas - as grandes linhas da nossa formação econômica, o mercado de trabalho e a marginalidade social, os desequilíbrios regionais, o meio ambiente no capitalismo avançado, a tecnologia e a criatividade cultural em países economicamente atrasados, dentre outros temas, entre outros - se articulam e ganham sentido.

Palavras-chave: dependência, subdesenvolvimento, pensamento de Celso Furtado, pensamento social brasileiro

\section{INTRODUÇÃO}

Sabe-se que o núcleo original de pensadores reunidos na Comissão Econômica para a América Latina - Cepal a partir de 1948, tendo à frente Raul Prébisch, enfatizou a industrialização latino-americana como um objetivo a ser perseguido pelos países da região como forma de alavancar seu desenvolvimento nacional e fugir às malhas de uma divisão internacional do trabalho

\footnotetext{
1 Pesquisa de Pós-doutorado de Igor Zanoni Constant Carneiro Leão, orientado pela Professora Dr. ${ }^{a}$ Maria Tarcisa Silva Bega apresentado em 2014.

${ }^{2}$ Possui graduação em Ciências Econômicas pela Universidade Estadual de Campinas (1978), mestrado em Ciência Econômica pela Universidade Estadual de Campinas (1986), doutorado em Ciência Econômica pela Universidade Estadual de Campinas (1994) e pós-doutorado em Ciências Sociais pela Universidade federal do Paraná(2014) . Atualmente é professor titular da Universidade Federal do Paraná. Email: igorzaleao@ yahoo.com.br
} 
que, de outra forma, os condenaria a um papel passivo e subordinado frente aos países centrais, bem como a uma situação reflexa sem dinamismo próprio tanto do ponto de vista material quanto social.

Esta percepção encontra-se, já, no Brasil, antecipada nos autores que pensaram originalmente no desenvolvimento a partir de uma racionalidade pública, centrada no Estado como locus coordenador de decisões políticas e econômicas, independente de sua filiação ideológica originária. Assim, ela pode ser encontrada tanto em Roberto Simonsen quanto em Caio Prado Júnior ou Ignácio Rangel e muitos outros. Entre eles, talvez o que mais tenha desenvolvido a ideia de passagem de uma economia periférica de matriz colonial para uma economia dita nacional tenha sido nosso maior historiador, Caio da Silva Prado.

Para este, a economia colonial é marcada pelo baixo desenvolvimento das forças produtivas, pela desigualdade e heterogeneidade sociais, pela ausência de soberania, pelo reduzido rol de direitos sociais, bem como pela fragilidade da democracia. A economia nacional, por sua vez, é caracterizada, muito mais como um objetivo a ser alcançado conscientemente no futuro com características opostas. Em Caio, essa transição marca-se por inúmeras rupturas com a ordem colonial, através de momentos históricos como a independência, a abolição, a república, a industrialização, a urbanização e outros, apontando para o futuro de forma escatológica e utópica, ao mesmo tempo em que como objeto de ação política determinada.

Não por acaso, a obra de Celso Furtado, em suas grandes linhas, corre paralela com este percurso anunciado por Caio Prado. Chama atenção, inclusive, que, embora Celso Furtado muitas vezes refira sua dívida para com a visão histórica de Marx, autor recriado de modo original como base para o seu pensamento da história brasileira por Caio Prado, o primeiro em momento algum rende homenagem ao pensamento deste último.

Outro ponto bastante conhecido consiste nos esforços realizados pela Cepal para informar o desenvolvimento industrial latino-americano através do planejamento e da planificação. São conhecidas as expectativas que cercavam, no pós-guerra, o estímulo a esse desenvolvimento por algo semelhante a um Plano Marshall para a região, e a importância do segundo governo Vargas na primeira metade dos anos cinquenta. Neste período, entre outras realizações, tem lugar um diagnóstico e o desenho de linhas centrais da industrialização pesada no país através da Comissão Cepal-BNDE, em larga medida utilizados, todavia com modificações não desprezíveis, no Plano de Metas, já no governo Kubitschek. Neste último, há um esforço ao mesmo tempo paralelo e 
convergente voltado para a região nordestina, com a criação da SUDENE, chefiada por Furtado, o caso mais flagrante de desequilíbrio regional no desenvolvimento brasileiro.

Como assinala Furtado (FURTADO, 1997, Tomo II, p.57), a transição para o modo industrial de crescimento, que teve um ápice nesses anos, não se baseou em aportes financeiros externos, mas em recursos tecnológicos e financeiros das empresas transnacionais que faziam sua entrada na economia mundial. A industrialização tardia no país fizera com que o mercado local fosse inicialmente abastecido por importações e é a demanda insatisfeita por estas que estimulava a produção local. Este é o cerne da industrialização, após a grande crise de 1929, até 1955, a assim chamada industrialização por substituição de importações.

Aspecto importante lembrado pelo autor no mesmo texto é que

Em face da escassez de produtos importados, surgiram empresas locais empenhadas em copiar equipamentos estrangeiros, modificar técnicas para substituir matérias primas importadas por produtos de origem interna e mesmo criar produtos novos capazes de tomar o lugar de artigos importados. O considerável número de patentes depositadas na época atesta o estado de efervescência da criatividade tecnológica. Equipamento têxteis, agrícolas, para a indústria do cimento, carrocerias de ônibus, uma miríade de produtos saia de oficinas semi-improvisadas. Dada a penúria que existia nos mercados desses bens, tudo que caía na rede era peixe, como se dizia na época. Essa experiência foi valiosa na constituição de uma classe empresarial voltada para a indústria no Brasil. A teoria da 'indústria infantil' podia ser evocada como fundamento doutrinário. Uma classe empresarial não se forma senão em um clima que estimule a iniciativa, inclusive no plano tecnológico, e num ambiente onde haja proteção para que as iniciativas não abortem. Essa combinação feliz te estímulo à iniciativa e proteção à empresa nascente deu-se no Brasil no período compreendido entre a grande depressão e o final da segunda guerra (op. cit., p. 58-59).

Este período traduziu-se em urbanização, elevação no nível médio de vida, formação de uma classe média e constituição de um parque industrial consideravelmente integrado. Ao mesmo tempo, ele se deu num contexto internacional de depressão prolongada e guerra, portanto de isolamento econômico relativo do Brasil. Este contexto transfigura-se, nos anos cinquenta, através de fortes taxas de crescimento do comércio internacional e nova estratégia das grandes empresas dos países centrais buscando abrir filiais em mercados que se integravam e especialmente para os quais havia proteção local, como no Brasil.

Assim, há uma ruptura, nos anos cinquenta, no sentido de que a industrialização pesada distancia o parque empresarial brasileiro da criação tecnológica. A iniciativa empresarial de uma burguesia brasileira se restringe, e a mentalidade industrial se torna pouco inclinada a uma produção tecnológica nacional. Este ponto, lembrado por outros autores da nossa formação econômica e 
política, como o próprio Caio Prado e Fernando Henrique Cardoso, que enfatizarão a existência no Brasil de uma burguesia associada, é de extrema importância no pensamento de Furtado, pois significa que a industrialização via grandes empresas alienígenas reproduzem no país estruturas que alienam destes centros de decisão, induzem uma tecnologia desvinculada daquela que seria necessária para nossa estrutura de mercado de trabalho e de distribuição de renda, ou seja, de nossa estrutura social, prendendo o país fortemente ao que Caio Prado denomina "imperialismo" e colocando obstáculos à transição rumo ao que este denomina uma economia nacional. Em Furtado, coloca-se aí uma peça chave no sentido da dependência econômica e política e de um subdesenvolvimento industrializado.

Essas considerações foram destacadas pelo autor num grupo de economistas e sociólogos reunido sobre o problema do desenvolvimento e do subdesenvolvimento a partir de junho de 1964. Nele, Furtado avança a ideia de que a tecnologia utilizada na industrialização periférica não corresponde aos padrões de consumo, de produtividade e de poupança de economias como a nossa, de baixos níveis de renda. Já aí se percebe que a concepção cepalina centro-periferia pressupõe o imperialismo, uma vez que a propagação do progresso técnico em seguida à revolução industrial inglesa era estritamente controlada pela Inglaterra, dentro da proposta de uma divisão internacional do trabalho teorizada por Adam Smith e David Ricardo com a doutrina dos custos comparativos. A formação do comércio internacional tornou-se, desde então, fruto de uma política deliberada de dominação no contexto da revolução industrial originária.

Por outro lado, na periferia, a medida que se diversificava o sistema produtivo tendia ser maior o peso de indústrias com elevado coeficiente de capital, o que levava à dependência tecnológica, impondo um montante de investimento por trabalhador muito acima da capacidade de poupança das populações periféricas. Esta dependência se desdobrava em uma dependência cultural, uma vez que o produto manufaturado importado concorria com o produto local com vantagem, determinando que técnicas seriam utilizadas. Essa dependência cultural incitava a diversificação do consumo, reduzindo o potencial de poupança e aumentando os requisitos da capitalização na indústria.

Era possível que reformas estruturais comandadas pelo Estado corrigissem esse quadro, mas elas teriam de ser profundas, e não havia forças sociais capazes de suportá-las política e ideologicamente. Ponto importante aí é que o grau de desenvolvimento industrial alcançado via 
grandes empresas internacionais interrompeu, de maneira geral, a formação de uma classe empresarial com uma ideologia nacionalista capaz de controlar os setores manufatureiros mais dinâmicos. A empresa nacional ficou restrita a setores secundários, crescendo a reboque dos setores dinâmicos. Noutras palavras, como afirmou Fernando Henrique Cardoso, houve uma “internacionalização do mercado interno”, ou seja, a relação entre a economia brasileira e os centros dinâmicos das economias centrais ocorre no próprio mercado interno da primeira.

Nos primeiros anos do exílio, Furtado mostra seu desalento com o quadro acima.

\begin{abstract}
O reconhecimento de que a sociedade brasileira estava marcada pela herança das sequelas da escravidão e pelas taras de um processo de colonização em que o controle do acesso às terras fora utilizado para explorar a massa da população, a ponto de desumanizá-la, e a visão de que o país acumulou considerável atraso no quadro de uma civilização implacável com os retardatários foram fatores decisivos na construção de meu projeto de vida. E é ilusão, que chegou a dominar meu espírito em certo momento, de que uma feliz conjuntura internacional - consequência da Grande Depressão dos anos 30 e do conflito mundial dos 40 - abrira uma brecha pela qual quiçá pudéssemos nos esgueirar para obter uma mudança qualitativa em nossa história, agora se desvanecia. O Brasil continuaria prisioneiro de suas estruturas anacrônicas, crescendo em benefício de uma minoria privilegiada, acrescentando cada ano pelo menos um milhão de pessoas à sua imensa legião de desnutridos, desabrigados, desvalidos (op. cit., p. 95-96).
\end{abstract}

De outra perspectiva, nos anos sessenta a política externa dos Estados Unidos, num momento em que este país gozava de grande afluência e Johnson propunha o projeto da Grande Sociedade, percebeu o quadro das transformações em curso em diversas áreas do planeta, resultantes da interdependência econômica imposta pela moderna tecnologia propagada pelos conglomerados internacionais, como produto de uma confrontação ideológica no interior da Guerra Fria. Os Estados Unidos passaram a considerar inevitável a intervenção nos assuntos internos de grande número de países, inclusive do Brasil. Estes deveriam ter como objetivo prioritário prevenir subversões sociais. Este quadro reforçou a ideia de que o subdesenvolvimento não é uma etapa na vida dos povos, mas uma formação de que se reproduz em distintos níveis de crescimento, com raízes políticas, econômicas e ideológicas.

Um aspecto central do subdesenvolvimento ligado a esse contexto é a reafirmação contínua da desigualdade no mercado de trabalho, uma vez que as estruturas sociais na periferia não tendem a se homogeneizar, pois os países subdesenvolvidos, entre outros aspectos, seguem de perto os padrões tecnológicos dos países industrializados. Por outro lado, a urbanização dos países de 
industrialização retardada decorre de modificações na estrutura ocupacional como o crescimento das atividades mercantis ligadas ao comércio exterior, a persistência de formas de organização précapitalista no campo, a penetração de técnicas modernas em certos setores da agricultura, o agravamento pela industrialização substitutiva da extrema concentração da renda, o aumento relativo das atividades estatais e a aceleração do crescimento demográfico. Nesse quadro, as massas dos países subdesenvolvidos não se transformam em trabalhadores inseridos em um sistema produtivo moderno que não pode criar pra elas empregos suficientes e adequados.

Nas estruturas subdesenvolvidas, a técnica moderna cria problemas de amplas projeções no plano social, cuja solução deve ter natureza política, envolvendo juízos de valor, o que faz com que a industrialização retardada ocorra em um quadro de grande instabilidade institucional. Nessas estruturas, as massas que se acumulam nas grandes cidades não estão capacitadas e organizadas para absorver os frutos do progresso técnico. O liberalismo que nasce desde Adam Smith como uma ideologia de preservação do status quo mesclada com preocupações com a igualdade social e a equidade, transformou-se em autoritarismo, ou num populismo incapaz de assegurar justiça social. A conquista de um regime que concilie desenvolvimento com distribuição social exige a organização de massas heterogêneas sem recair na manipulação da opinião pública de forma personalista. Essa conquista está por ser feita, e o que vemos é um país politicamente instável, pois o excesso de concentração de renda provoca instabilidade social ao mesmo tempo em que a redistribuição de renda deve ser feita sem frustrar o crescimento.

Furtado parece, aí, preocupado com uma distribuição que preserve capacidade de poupança assim como estabilidade política. Pensa que o autoritarismo é danoso por restringir a participação da cidadania na política e priva o poder de controle social. Por outro lado, pensa também que o liberalismo reformista não poderá ter lugar enquanto não for vencido o subdesenvolvimento, situação na qual o Estado deve ter funções complexas e os problemas políticos não serão solucionados pela assimilação de novas técnicas. Em resumo, a construção de um quadro institucional que respalde os ideais de liberdade, bem estar e tolerância, terão de ser construídos de forma própria às condições presentes em uma sociedade subdesenvolvida como a brasileira.

Para o autor, que pensa em termos macroeconômicos dentro de um paradigma matizado pela teoria neoclássica (embora, é claro, completamente livre de sua visão estática e de equilíbrio, pois seu pensamento é original, guardando da Cepal o respeito por uma visão historórica e dinâmica, que 
haure da Escola Histórica Alemã, além de Marx), a poupança tem um papel decisivo no crescimento como pré-condição para o investimento. Daí essa preocupação com a capacidade de poupança a qual, todavia, se relaciona menos com a disponibilidade de recursos para uma burguesia industrial que a seu ver tem um papel subordinado na dinâmica econômica, ou na superação do subdesenvolvimento e da dependência, como foi observado acima.

Ao contrário, o autor pensa, sobretudo, em uma poupança que possa ser apropriada mediante a política fiscal pelo Estado. Como ele explica exaustivamente em sua obra (por exemplo, FURTADO, 1997, Tomo III, p. 230), não se sai do subdesenvolvimento pelas simples forças de mercado, sendo necessário um esforço deliberado, moderando certas formas de consumo e elevando a taxa de poupança, através de uma política fiscal rigorosa e uma ação de conjunto sobre a economia através do planejamento sancionadas por um amplo consenso social. Há uma preocupação com o Estado fraco diante das elites internacionalizadas, e com sua regeneração diante das formas extremadas de corporativismo no país:

\footnotetext{
Nos países do mundo desenvolvido, o problema está em fortalecer instituições da sociedade civil, inclusive aquelas que se apoiam na opinião pública internacional. Mas nos países cujos sistemas econômicos devem ser reconstruídos para erradicar tendências estruturais à concentração da renda e ao desperdício de recursos, o problema é de outra natureza, pois se trata de reabilitar o próprio instrumento de reconstrução (op. cit., p. 185).
}

Não se trata de corroborar, enfatize-se, o autoritarismo, mas perceber que a correção do subdesenvolvimento depende de um processo político que a sociedade somente pode realizar por meio do Estado. Este é um instrumento de uma sociedade consciente da importância crucial do Estado na construção de uma "economia nacional", para usar um termo de Caio Prado Júnior, isto é, de uma economia voltada para as necessidades da população que vive e trabalha nessa sociedade (LEÃO, 1994).

Ainda no governo Goulart, essa percepção fica clara no texto que escreve diante da crise política em curso e das eleições parlamentares de fins de 1992, com o objetivo de esclarecer ideias centrais capazes de reunir as forças progressistas em torno da restauração do presidencialismo e de um congresso que pudesse apoiar as reformas necessárias para reduzir o custo social do desenvolvimento. Neste texto, Furtado propõe um programa mínimo centrado na reforma agrária, 
na reforma fiscal, reforma universitária, estatuto disciplinar do capital estrangeiro e reforma bancária.

Este programa parte do diagnóstico de que as tensões sociais e políticas em curso no país ligavam-se ao próprio desenvolvimento num contexto de um marco institucional obsoleto. Assim, grande parte da população permanecia isolada da vida política pelo velho sistema de organização agrária, o governo é fragilizado por um sistema fiscal que tornou o desenvolvimento altamente concentrador de renda e o sistema bancário, a máquina administrativa, o sistema universitário, entre outros, foram superados pela transformação do país, de um simples exportador de produtos primários a uma nação industrial a partir da década de 30. Tudo isto exige uma ação do governo efetiva na solução de problemas básicos inclusive pelo investimento maciço em setores estratégicos. São estas mesmas preocupações e alternativas que informam a atuação da SUDENE e o Plano Trienal (FURTADO, 1997, Tomo II).

Como se sabe também, Furtado foi uma personagem, entre outas, derrotadas pelo curso que tomou a política no Brasil com a Revolução de 1964 e suas alternativas sociais e econômicas, desembocando no chamado milagre brasileiro, que, para o autor, consistiu simplesmente em uma intensificação do processo de concentração da renda, dados o arroxo salarial e o desmantelamento das resistências sindicais, o que gerou recursos para financiar a expansão de bens duráveis ao invés de investimentos em capital fixo, em especial na infraestrutura. Nesse sentido, o Brasil se mantinha nas suas linhas tradicionais de subdesenvolvimento dependente, tanto mais que a política externa americana dera forte respaldo ao golpe e aos governos militares que se seguiram. Estas ideias tomaram forma em livro de 1972, Análise do 'modelo' brasileiro, publicado no Brasil pela editora Civilização Brasileira.

Neste livro, o autor explica que a dinâmica da economia brasileira estava determinada pela ação das empresas transnacionais, respondendo por inovações de produtos e processos e pelo Estado, que adequou o perfil da demanda às necessidades do progresso tecnológico comandado por estas empresas. As empresas nacionais, por sua vez, continuavam a desempenhar uma ação complementar. Crucial, aí, é a concentração de renda:

Modificando os programas dos diferentes titulares de renda, o governo põe em marcha uma série de processos que afetam o grau de utilização da capacidade produtiva já existente, a composição dos novos investimentos e a intensidade do fluxo de entrada de recursos 
externos. Criam-se, assim, condições para que as empresas transnacionais maximizem suas possiblidades de ação. Os resultados se farão sentir direta e indiretamente nas duas relações estruturais que comandam o crescimento da economia: a taxa de investimento e a produtividade média do capital (FURTADO, 1997, Tomo III, p.213).

No mesmo livro em que analisa o modelo brasileiro, de 1972, Furtado responde à ideia vulgarizada de que "é preciso deixar o bolo crescer e depois reparti-lo". Para o autor, a concentração de renda implicou numa adaptação do consumo aos esquemas das grandes empresas multinacionais comandando o sistema de produção, o que veio a agravar as desigualdades regionais, manter o atraso relativo de grande parte da população, em especial da população negra, inserida nos grupos sociais de mais baixa renda real, tudo isto caracterizando uma responsabilidade histórica considerável diante dos autodesignados tecnocratas, que se pensavam no poder por seus méritos intelectuais (e não por sua funcionalidade ao processo problemático de manter a dinâmica perversa do subdesenvolvimento dependente). Observe-se que, nessa passagem, Furtado não está indicando a necessidade de uma rápida e mais equitativa distribuição de renda, ou realçando a importância da concentração dessa renda na configuração do milagre, tão somente, mas acentuando as articulações entre autoritarismo, dependência tecnológica e política e desigualdade social crescente em nosso subdesenvolvimento industrializado. Como diz o adágio, os grandes mestres sempre se repetem, e Furtado, aqui, repete suas agudas percepções da história do nosso capitalismo.

Furtado voltará muitas vezes ao problema da heterogeneidade social, por exemplo, em Brasil - a construção interrompida. Neste texto, assinala explicitamente que "A teoria do subdesenvolvimento cuida do caso especial de situações em que aumentos de produtividade e assimilação de novas técnicas não conduzem à homogeneização social, ainda que causem a elevação do nível de vida médio da população" (FURTADO, 1992, p. 39). O subdesenvolvimento resulta de um desequilíbrio na assimilação das tecnologias industriais modernas, incidindo sobre o estilo de vida mas em prejuízo da absorção de técnicas produtivas mais eficazes em termos sociais.

No Brasil, a modernização, longe de beneficiar o conjunto da população, em uma hipótese que Furtado considera escolar, agravou a concentração de riqueza e renda já existente, fazendo com que apenas o segmento da população em condições de controlar os aumentos de produtividade permitidos por vantagens comparativas no comércio internacional e pela industrialização pudesse ser contemplado. Neste contexto, a adoção de padrões de consumo imitados de sociedades com níveis médios de renda muito maiores provoca o dualismo social e impede, portanto, que o 
crescimento da produtividade e da renda média seja suficiente para produzir o verdadeiro desenvolvimento, que implica a homogeneização social. Não se trata, aí, de um determinismo político ou econômico, mas de uma derrota no plano das lutas sociais e de alternativas. Pensando no Brasil entre os anos 50 e início dos 90, Furtado observa:

A ninguém escapa que o considerável aumento de produtividade ocorrido no Brasil nos últimos quarenta anos operou consistentemente no sentido de concentrar os ativos em poucas mãos, enquanto grandes massas da população permaneciam destituídas do mínimo de equipamento pessoal com que se valorizar nos mercados. Como modificar o mecanismo que conduz a essa perversa distribuição de ativos, ao nível das coisas e das habilitações pessoais, é a grande interrogação. Não cabe dúvida de que aí reside o fator decisivo na determinação da distribuição primária da renda. E das forças do mercado não se pode esperar senão que assegurem a reprodução dessa situação, e mesmo alimentem a tendência à sua agravação (op. cit., p. 54).

Se o processo de industrialização substitutiva, ao implicar a empresa internacional como um dos seus eixos centrais nos anos 50 e com isto vulnerabiliza os centros internos de decisão na economia brasileira, desde o final dos anos 60 se dá o fenômeno do crescente endividamento externo, que caminha pari passu com o endividamento interno, e o crescimento da dívida pública. Em A nova dependência - dívida externa e monetarismo, de 1982, Furtado observa que, no Brasil, como em toda América Latina, o rápido endividamento dos anos 70 permitiu, em um primeiro momento a elevação da taxa de investimento, mas, a partir de certo momento, com a elevação dos juros internacionais e a ascensão de doutrinas monetaristas nos Estados Unidos e na Inglaterra, o duplo endividamento externo/interno conduziu a uma reorientação dos investimentos para aumentar as exportações, a compressão das importações e a redução do ritmo de crescimento econômico. Esse processo, como se sabe, conduzirá a uma combinação entre recessão e inflação, com suas consequências perversas sobre o mercado de trabalho, entre outros problemas.

Nesse contexto, um país periférico como o nosso precisou submeter-se a uma crescente internacionalização monetária, financeira e comercial. Os centros de decisão na economia brasileira tornam-se ainda mais vulnerabilizados e se assiste a crescente perda de autonomia das autoridades monetárias e redução do alcance dos instrumentos da política econômica. Essa semiparalisia dos centros nacionais de decisão no uso dos instrumentos tradicionais de política monetária, cambial e fiscal, deve-se, portanto, à integração de partes fundamentais do aparelho produtivo a estruturas tecnológicas e empresariais externas, revelando, na periferia, as mudanças estruturais do conjunto 
do sistema capitalista após os trinta anos em que este foi comandado pelo ideário e pelas instituições de corte keynesiano, bem como a desregulamentação, concentração/centralização e internacionalização dos grandes conglomerados industriais e bancários dos países do centro.

Em grande parte da América Latina, bem como em outras regiões periféricas do globo, adotou-se, diante desse cenário de instabilidade, inflação e desemprego, a doutrina monetarista difundida especialmente por Milton Friedman, mas elaborada desde há muitas décadas por pensadores liberais, buscando alternativas sociais e ideológicas ao paradigma keynesiano:

A doutrina monetarista tem sido utilizada na América Latina para legitimar o processo de internacionalização, que é apresentado como uma transição para formas superiores de organização econômica. Restituir aos mercados (internos e externos) o papel central na alocação de recursos e na remuneração dos fatores seria condição sine qua non para restaurar a racionalidade econômica e assim abrir caminho a melhorias efetivas do bem estar social. Essa doutrina tem pelo menos a virtude de explicitar o modelo que está embutido no vasto processo de reestruturação em curso no sistema capitalista (FURTADO, 1982, p. 129).

Neste momento, Furtado está chamando a atenção para a afirmação de uma dependência financeira crescente e para a proposta monetarista, ideológica e politicamente extremada, que privaria o país de qualquer meio autônomo de decisão do plano instável da economia internacional reestruturada em termos tecnológicos, empresariais e geopolíticos. Como se sabe, o Brasil, após inúmeros ensaios de heterodoxia no plano da política econômica a partir da Nova República, embora nunca tenha optado por um monetarismo estrito, nos anos 90 o cenário de recessão, dívida externa, paralisia crescente da ação pública e inflação, termina por implicar um receituário próximo ao preconizado pelo monetarismo.

Desde o Plano Collor, culminando com o Plano Real e o programa de reestruturação da dívida externa, passando pela privatização e desnacionalização de um rol significativo de empresas estatais e nacionais privadas, o Estado procura acentuar uma política econômica fortemente integrada aos circuitos financeiros, produtivos e comerciais externos. O monetarismo terá um núcleo forte de influência sobre o conjunto da política econômica no tripé câmbio flexível/ juros elevados/ superávit primário, reduzindo, como indicara Furtado, a capacidade nacional de decidir o nível de investimento e a taxa de crescimento do produto, ao mesmo tempo em que condicionará o alcance das políticas sociais. Este é o quadro ainda presente nos governos seguintes já no século 
XXI. Como dramaticamente anunciara Furtado, diante de nós está uma construção interrompida, de forma inerente à lógica do subdesenvolvimento e da dependência, cuja conformação em essência se mantém, no interior das transformações na economia mundial.

Em Criatividade e dependência na civilização industrial, de 1978, Furtado observa que a instabilidade da economia internacional deve-se a sua falta de coordenação, uma vez em que as atividades econômicas continuam estruturadas em um marco coordenador nacional, e que as decisões envolvendo os estados nacionais, face as empresas transnacionais, não possuem coerência interna. As relações de forças entre os centros de decisão tendem a ampliar o espaço da acumulação nesse plano global, mas isto se faz sem que seja possível obter estabilidade no plano nacional, isto é, condições de pleno emprego e equilíbrio nas contas externas de cada país.

Tal ordem internacional demanda controle da tecnologia, controle das finanças, controle dos mercados, do acesso às fontes de recursos não-renováveis, bem como do acesso à mão de obra barata. As posições de força dos estados ou dos grandes grupos econômicos, em seu relacionamento, produzem uma estrutura coordenada, gerando dependência dos países periféricos. Assim, para o autor,

\begin{abstract}
A luta contra a dependência não é outra coisa senão um esforço de países periféricos para modificar essa estrutura. Coligações de países permitem ocasionalmente obter a massa crítica requerida para o controle de um recurso, ou articular combinações de recursos de alta eficácia na geração de poder. Controlar os estoques de um produto é importante, mas ainda mais importante é dispor de recursos financeiros para prolongar esse controle. Dispor de recursos de petróleo é uma arma, mas a eficácia dessa arma pode aumentar consideravelmente se se consegue organizar globalmente a oferta de petróleo no mercado internacional (FURTADO, 1978, p. 104-105).
\end{abstract}

Dentre esses recursos de poder, o primordial é o controle da tecnologia, o que para Furtado consiste na expressão final da criatividade humana dentro da civilização industrial. Esta pode ser vista como fruto de uma orientação da criatividade humana, favorecendo a acumulação e a reprodução de certas estruturas sociais. As empresas transnacionais nada mais são do que o aprofundamento da dominação tecnológica na época da difusão por todo o globo de atividades industriais. Quando pensa em dependência como um aspecto da cultura, ou seja, na dependência cultural, todos esses aspectos são levados em conta, de onde se segue que:

Contudo, não se deve perder de vista que a luta contra a dependência não é senão um aspecto do processo de desenvolvimento, e que não existe sem a liberação da capacidade 
criadora de um povo. Quiçá o aspecto mais negativo da tutela dos sistemas de produção na Periferia, pelas transnacionais, esteja na transformação dos quadros dirigentes em simples correias de transmissão de valores culturais gerados no exterior. O sistema dependente perde a faculdade de conceber os próprios fins (op.cit., p. 113).

Em Brasil: a construção interrompida, Celso Furtado reflete sobre a dependência tecnológica e financeira no contexto da instabilidade internacional em termos de uma mudança cultural que abranja o conjunto dos países, em um deslocamento do curso da civilização que trocaria o seu eixo da lógica dos meios a serviço da acumulação para uma lógica dos fins em função do bem estar social, da liberdade e da cooperação entre os povos. A ação política seria colocada, nesse contexto, em função de um desenvolvimento posto ao alcance de todos os povos e ao mesmo tempo preservando o equilíbrio ecológico:

\begin{abstract}
O objetivo deixaria de ser a reprodução dos padrões de consumo das minorias abastadas para ser a satisfação das necessidades fundamentais do conjunto da população e a educação concebida como desenvolvimento das potencialidades humanas nos planos ético, estético e da ação solidária. A criatividade humana, hoje orientada de forma obsessiva para a inovação técnica a serviço da acumulação econômica e do poder militar, seria dirigida para a busca da felicidade, esta entendida como a realização das potencialidades e aspirações dos indivíduos e das comunidades vivendo solidariamente (FURTADO, 1992, p. 77).
\end{abstract}

Furtado está dialogando, aí, com preocupações do chamado Clube de Roma no seu Limites do crescimento e com uma série de trabalhos desenvolvidos na Cepal e na Organização das Nações Unidas, diálogo que surge no início dos anos setenta, após a primeira crise do petróleo, a guerra no Oriente Médio e o fim do padrão de regulação econômico internacional criado no pós-guerra. Em seu ensaio $O$ mito do desenvolvimento econômico, de 1974, Furtado dialoga com a preocupação do Clube de Roma acerca de uma eventual universalização das formas de vida dos povos ricos por todos os povos, causando uma pressão intolerável sobre os recursos não renováveis, a poluição do meio ambiente e o inevitável colapso do sistema econômico mundial.

A percepção do autor neste texto é de que a economia mundial, ao concentrar renda, exclui dos benefícios do desenvolvimento a grande maioria da humanidade. O subdesenvolvimento se constitui, no fundo, em um fenômeno de dependência tecnológica e de mimetismo cultural, que não pode realizar a promessa de reproduzir as formas de vida dos países ricos. Isto faz com que seja necessário modificar o enfoque sobre a acumulação, restringindo o econômico a um papel 
instrumental a partir de objetivos sociais. É esta mesma conclusão que Furtado repete em Brasil: $a$ construção interrompida, deslocando o acento dos países subdesenvolvidos para o conjunto da civilização humana, realçando a necessidade da espécie de evitar sua autodestruição.

Assim, já em $O$ mito do desenvolvimento econômico o autor afirmava:

A conclusão geral que surge dessas considerações é que a hipótese de generalização ao conjunto do sistema capitalista das formas de consumo que prevalece atualmente nos países ricos não tem cabimento dentro das possibilidades evolutivas aparentes desse sistema. E é essa a razão fundamental pela qual uma ruptura cataclísmica, num horizonte previsível, carece de fundamento. $\mathrm{O}$ interesse principal do modelo que leva a essa ruptura cataclísmica está em que ele proporcione uma demonstração cabal de que o estilo de vida criado pelo capitalismo industrial sempre será o privilégio de uma minoria. $\mathrm{O}$ custo, em termos de depredação do mundo físico, desse estilo de vida é de tal forma elevado que toda tentativa de generalizá-lo levaria inexoravelmente ao colapso de toda uma civilização, pondo em risco as possibilidades de sobrevivência da espécie humana (FURTADO, 1997, Tomo III, p. 226).

Daí ser necessário concluir que o desenvolvimento se constitui em um mito ou uma meta inalcançável para o conjunto dos povos do terceiro mundo. Nos textos escritos posteriormente, Furtado percebe como a busca mimética desse desenvolvimento econômico coloca em risco a própria civilização em uma crise já não restrita a aspectos econômicos ou políticos. Isso é especialmente verdade para o autor no quadro da instabilidade e crise internacionais a partir das últimas décadas do século XX.

Esta preocupação é atual na medida em que várias regiões do globo ainda buscam essa via de consolidação ou afirmação econômica e geopolítica, como ocorre com países como a China e o próprio Brasil, que vêm difundindo por vários segmentos de sua população uma cultura material centrada em bens valorizados culturalmente como o automóvel. Conforme colocamos acima, no sentido contrário ao desejado por Furtado, o Brasil, apesar de um conjunto de conquistas sociais como a elevação dos patamares reais do salário mínimo, formas de combate à pobreza através de programas como o Bolsa Família, vive hoje um quadro de avanço democrático travado por mimetismo cultural e administração monetarista em sentidos significativos de sua política econômica. Contudo, para nosso autor, o subdesenvolvimento só pode ser vencido em um novo marco civilizatório global, incluindo centro e periferia e eliminando essa polaridade. 
Nas páginas seguintes retomamos brevemente a exposição sobre os conceitos estudados acima de subdesenvolvimento e dependência a partir de um texto escrito para o Banco Mundial em 1987 pelo nosso autor, Entre inconformismo e conformismo, e reproduzido no terceiro volume de sua obra autobiográfica. Neste texto, o autor lembra como, a partir de Friedrich List e seu conceito de sistema de forças produtivas, isto é, a compreensão das atividades produtivas como um todo articulado, compreensão esta que deve anteceder a de seus elementos constitutivos, a economia política da Cepal concebeu uma visão global derivada da história que veio a ser conhecida como "estruturalismo".

Para este estruturalismo latino americano o comportamento das variáveis econômicas depende fortemente de parâmetros não econômicos que se definem e transformam historicamente, fato este particularmente relevante quando se estuda sistemas econômicos heterogêneos em termos sociais e tecnológicos como as economias subdesenvolvidas. Assim, a compreensão do subdesenvolvimento prioriza a análise das estruturas sociais para compreender o conjunto da formação capitalista na periferia, reinventando uma tradição que vem da escola histórica alemã e do pensamento marxista para os países desta região.

Por outro lado, a teoria da dependência se baseia numa visão global do capitalismo como um sistema expansivo e articulado de formações sociais heterogêneas, projetando-se nos países de industrialização tardia. A dependência se manifesta, a princípio, no plano cultural como transplante de padrões de consumo, adotados ainda no período da economia primária exportadora, e a seguir, com a industrialização, transmuta-se em uma dependência tecnológica que se inscreve na estrutura produtiva no período de substituição de importações. A dependência liga-se a um crescimento econômico concentrador de renda e socialmente desigual, e o capitalismo global apoia-se na dicotomia desenvolvimento-subdesenvolvimento, que intitula o livro em que Furtado reúne seus primeiros textos em economia. Como indica Furtado,

Em síntese, o que caracterizou a formação da periferia foi a dinamização da demanda modernização - em condições de um relativo imobilismo social causado pelo lento desenvolvimento das forças produtivas. O que veio a chamar-se de subdesenvolvimento não é outra coisa senão a manifestação dessa disparidade entre o dinamismo da demanda e o atraso na acumulação produtiva. Este último tem origem na forma de inserção na divisão internacional do trabalho e aquele, na penetração dos padrões de consumo do centro (FURTADO, 1997, Tomo III, p. 32). 
A evolução no sistema produtivo nos países periféricos conforma um processo adaptativo impulsionado pelas forças externas e internas que definem o padrão da demanda final, fazendo com que as estruturas sociais nestes países tenham uma especificidade, a saber, a heterogeneidade social e produtiva, o desemprego disfarçado, a fragilidade do Estado, a tendência ao autoritarismo e à ausência de democracia, enfim, todas as características de um país subordinado a uma ordem global da qual se beneficiam elites descompromissadas com as necessidades do conjunto da população que nele vive e trabalha. Este ponto foi exaustivamente trabalhado por Caio Prado Júnior, especialmente em A revolução brasileira, entre outros textos, bem como por outros autores que souberam, como Furtado, captar os elementos fundamentais de um pensamento desenvolvimentista latino americano e acentuaram o papel do planejamento e do Estado na evolução das estruturas sociais no sentido da superação desse estado de coisas.

Para Furtado, é possível a superação dos problemas acima no plano da política. No final da ditadura militar, Furtado escreve:

Há exemplos, na história de outros povos, de avanços rápidos no plano político após o despertar de uma longa noite de imobilismo, como se a sociedade fosse dotada de um inconsciente, onde laboram forças criativas que ampliam o horizonte de possibilidades futuras. Em todo caso, a rica fermentação de ideias e iniciativas políticas que se observam no Brasil neste fim de 1984 parece traduzir uma ânsia de recuperação do tempo perdido (op. cit. p. 38).

Todavia, como ficou claro no artigo, reiteraram-se e reinventaram-se o subdesenvolvimento e a dependência, mantendo-se, embora, suas características centrais, o que levou o autor a pensar numa superação da dicotomia desenvolvimento-subdesenvolvimento dentro de um novo marco civilizatório global. O artigo pretende ter indicado uma continuidade básica política e ideológica ao longo de todo o fértil trabalho de uma vida desenvolvido pelo autor, que pode ser considerado nosso maior economista e um dos nossos pensadores fundamentais. Enfatize-se esta afirmação porque, embora bebendo em diversas fontes, a Cepal criou um pensamento latino-americano próprio diante do problema do subdesenvolvimento e da posição retardatária de nosso capitalismo periférico e dependente, e o próprio Furtado foi um pensador com características próprias que não autorizam vêlo como um cepalino tout court nem como um autor excessivamente próximo a posições de outros dependentistas como Fernando Henrique Cardoso, citando-se não casualmente este exemplo. 
Para esclarecer este último ponto, já encaminhando a conclusão do artigo, retomemos Carlos Mallorquin em Celso Furtado: um retrato intelectual, de 2005, ao comparar a concepção de desenvolvimento de Fernando Henrique Cardoso e de Celso Furtado. Assim, examinando uma noção central, por exemplo em Formação econômica do Brasil, a de fluxo de renda que guia a análise desse livro do desenvolvimento do capitalismo brasileiro desde suas origens coloniais até os primórdios da industrialização substitutiva, Fernando Henrique Cardoso observa:

Se a análise de Furtado tivesse parado nesse ponto, ele teria redefinido a teoria de Prebisch apenas por meio de uma formalização de sabor neoclássico com condimento keynesiano. Mas o autor introduziu outras ideais que até certo ponto, e paradoxalmente, baseiam as modificações de estrutura, concebidas estritamente na forma acima mencionada, em modificações regidas pela demanda: e esta última, para Furtado, não pode ser vista separadamente do sistema de referências individuais e coletivas (CARDOSO in MALLORQUIN, 2005, p.336).

Para Mallorquin, a avaliação de Cardoso sobre Furtado supõe que cada sociedade está governada e organizada por valores divergentes, impedindo perceber de antemão a diferença entre desenvolvimento e crescimento para cada uma das sociedades. Nesse sentido, Furtado teria rompido parcialmente com a análise cepalina, conservando-se dentro de um estilo teoricamente ortodoxo. Novamente, segundo Cardoso:

A síntese proposta por nosso autor cai desde o aproveitamento do instrumental de análise corrente na economia "ortodoxa" até o das preocupações pela ênfase nos elementos estruturais e na racionalidade no uso dos fatores, mas mantém a fé no mais clássico que o século XIX legou à ciência social contemporânea: a ideia de otimização do uso de fatores e a crítica iniciada pelo marxismo à pura racionalidade formal (op. cit., p. 336).

Para Cardoso, portanto, Furtado parece envolvido em uma "promiscuidade teórica e conceitual irremediável". Uma oposição semelhante se encontra em Werner Baer, que "avalia negativamente sua teorização porque, segundo ele, esta apresenta certo ecletismo e heterogeneidade", o que faz com que Furtado deixe de ver de forma mais sistemática o processo de desenvolvimento (MALLORQUIN, 2005, p. 336). Mallorquin rejeita com pertinência a visão de Cardoso e de Baer sobre Furtado, como segue: 


\begin{abstract}
Mas o significado dos conceitos e sua consistência devem ser avaliados em termos de seus laços entre si, assim como da forma em que constituem seus objetos; está fora de lugar a busca da suposta paternidade ou procedência dos conceitos para examinar seu rigor. Isso significa que os conceitos contraditórios que pudessem ser encontrados no discurso não são uma espécie de travesti, e sim categorias que requerem uma reelaboração ou seu deslocamento da formação discursiva em questão. Os problemas que alguns conceitos suscitam em qualquer formação discursiva só serão resolvidos por meio de sua transformação e/ou novas maneiras de articulá-los a outras categorias; esses problemas não surgem pela incapacidade teórica dos supostos criadores dos conceitos, mas como resultado dos problemas que emanam à raiz de seu uso. A construção teórica de Furtado, pelo menos a partir de 1958, procura constituir uma nova região "econômica", a partir de noções sociológicas e históricas, e é nesses termos que deve ser avaliado seu alcance (MALLORQUIN, 2005, p. 336-337).
\end{abstract}

Em conclusão, a obra de Furtado continuamente se refaz, num processo de transformação e renovação teórica, reelaborando conceitos e objetos ao longo da trajetória que ele documentou e da qual fez uma exegese das transformações do capitalismo global e do desenvolvimento brasileiro. Ao fazer isso, Furtado manteve coerência ideológica e analítica notável, mantendo-se rigorosamente fiel a pressupostos como a busca necessária para nossa autonomia cultural da soberania, democracia, igualdade social e outros objetivos que explicitou juntamente com uma tradição do pensamento desenvolvimentista que remonta a diversos dos nossos autores clássicos, dentre os quais sobreleva Caio Prado Júnior.

\title{
REFERÊNCIAS
}

FURTADO, Celso; Obra autobiográfica, 3v. Conteúdo: v1: Contos da vida expedicionária, A fantasia organizada; v2: Aventuras de um economista brasileiro, A fantasia desfeita; v3: Entre inconformismo e reformismo, Os ares do mundo. Rio de Janeiro: Editora Paz e Terra, 1997;

; Desenvolvimento e subdesenvolvimento. Rio de Janeiro: Contraponto: Centro Internacional Celso Furtado, 2009;

; Análise do 'modelo’ brasileiro. Rio de Janeiro: Editora Civilização Brasileira SA., 1972;

; A nova dependência: dívida externa e monetarismo. Rio de Janeiro: Editora Paz e Terra, 1982;

; O mito do desenvolvimento econômico. São Paulo: Círculo do Livro, ?;

; Brasil: a construção interrompida. Rio de Janeiro: Editora Paz e Terra, 1992;

; Criatividade e dependência na civilização industrial. São Paulo: Círculo do Livro, ?; 
MALLORQUIN, Carlos; Celso Furtado: um retrato intectual. São Paulo: Xamã; Rio de Janeiro: Contraponto, 2005;

CARDOSO, Fernando Henrique; FALLETO, Enzo; Dependencia y desarrollo em América Latina. Cidade do México: Siglo XXI, 1978;

PRADO JÚNIOR, Caio; Formação do Brasil contemporâneo: colônia; São Paulo: Brasiliense, 1942 ;

LEÃO, Igor Z. C. Carneiro; A matriz teórica de Caio Prado Júnior: a nação inconclusa, tese, Instituto de Economia da Universidade Estadual de Campinas, 1994;

\title{
Dependency and underdevelopment in the work of Celso Furtado
}

\begin{abstract}
This article clarifies the relationship between dependence and underdevelopment second Celso Monteiro Furtado. They were subjected to an exhaustive work of this author in all its vast production and are clarified tersely in his Autobiographical work. Although Furtado undoubtedly be our greatest economist, and more than that, one of the "Brazil of interpreters," so it is very well known and recognized, their books can be read in many opticians, because they speak of a large set of problems and issues ., within the larger question of development and economic and social formation of the country, however, the dependence of notions and underdevelopment are central, a hard core around which its various themes - the main lines of our economic formation, the market work and social marginality, regional imbalances, the environment in advanced capitalism, technology and cultural creativity in economically backward countries, among other topics, among others - articulate and gain meaning.
\end{abstract}

Keywords: dependence, underdevelopment, thinking of Celso Furtado, Brazilian social thought 